\title{
Boundary Crossing Support in Part-Time Higher Professional Education Programs
}

\author{
Margit Arts $^{1}$ (D) - Larike H. Bronkhorst ${ }^{2}$
}

Received: 18 July 2019 / Accepted: 12 November 2019 / Published online: 6 December 2019

(C) The Author(s) 2019

\begin{abstract}
As learning societies necessitate continuous education, a growing number of part-time programs are being offered. A key challenge for part-time programs is adequately supporting students in connecting their learning within the program to their work life, which in contrast to dual education is not part of the program. To better understand such boundary-crossing support in part-time higher professional education, this explanatory sequential mixed-methods study was conducted. A large-scale study, consisting of quantitative data analysis of the Dutch National Student Survey, confirmed that part-time programs $(n=600)$ differ in perceived boundary crossing, with a medium effect size of $\eta 2=.13$, and that factors postulated in the literature are related. An in-depth cross-case analysis of the boundary-crossing support provided in four purposefully selected part-time higher education programs (with high and low perceived support) indicated that brokers, boundary objects, hybrid practices, boundary interactions, degrees of freedom, degrees of clarity, and supervision are ways to support boundary crossing. These findings provide actionable strategies by which parttime higher professional education programs can support student learning across contexts.
\end{abstract}

Keywords Higher professional education · Part-time education · Boundary crossing · Learning across contexts $\cdot$ Mixed-methods

Margit Arts

margit.arts@hku.nl

1 Centre for Lifelong Learning and Educational Innovation, University of the Arts Utrecht, Nieuwekade 1, 3511 RVUtrecht, The Netherlands

2 Department of Education, Utrecht University, Heidelberglaan 1, 3584 CSUtrecht, The Netherlands 


\section{Introduction}

The way I look at part-time education is that you need a good combination of work, internships, and education. I'd love to put that in a mixer and combine these elements to foster learning. But I kind of experience that as separate parts. I try to guide [students] as well as possible. [...] You have to differentiate enormously with part-time students. There will be students who already have 10 years of work experience, and they need less; they need a partner to share ideas and perspectives [...] The young people, 24 and 25, who just finished their main education, they really need a lot more. (Elvira, teacher at a part-time program)

Today's learning society, with its rapidly changing labor market and delayed retirement, calls for an increasingly educated workforce (Organisation for Economic Co-operation and Development 2013). The need for greater participation in higher education is advanced from different perspectives, including empowerment, economic growth (Biesta 2006), and the expanding importance of qualification as a result of credential inflation (Fuller 2001), all stressing the need for a more accessible and flexible educational system (Broek and Hake 2012; Field 2000). Likewise, governments emphasize the necessity of continuous education and the importance of a professional education system that provides a wide range of flexible learning opportunities, including part-time education (Ministerie van Onderwijs, Cultuur en Wetenschap 2018).

To respond to these changing demands, professional education in the Netherlands offers a growing number of part-time programs (Ministerie van Onderwijs, Cultuur en Wetenschap 2018), where professionals work and study simultaneously. The challenges for programs involved in supporting learning across contexts are explicated by the quote from Elvira, a teacher participating in this study. Better alignment of the needs of higher education part-time professional programs and the professionals participating in them has also been called for (Vereniging Hogescholen 2018) in other European countries (European Commission 1995; OECD 2013).

Research shows that, although challenging, connecting learning across different contexts is possible and can contribute to engagement and enrich learning (e.g., Akkerman and Bakker 2011; Bronkhorst \& Akkerman 2016; Tuomi-Gröhn et al. 2003). Strategies for supporting students in doing so have been investigated in the context of dual education (for a review see Schaap et al. 2012). However, in part-time education, the work setting is not part of the program, and each student brings his or her unique work setting perspective. Moreover, diversity is not limited to work contexts, as students in part-time programs also tend to differ in terms of age and (work) experience. Consequently, part-time educational programs are not able to rely on alignment with the work setting, but need to develop open-ended ways of providing support for student learning across contexts.

Adopting a boundary-crossing perspective, this article focuses on identifying the different ways to provide support for learning across contexts that part-time programs (can) offer. The findings revealed here may provide actionable strategies for part-time higher professional education programs to support students' learning across contexts, as well as a better theoretical understanding of what such open-ended support entails. 


\section{Theoretical Framework}

Similar to dual education programs (Endedijk and Bronkhorst 2014), learning during part-time education occurs in at least one formal educational setting and one or more informal work settings. Whereas learning and its outcomes in formal education settings are usually typified as abstract and codified, learning in informal settings is generally considered to be context-bound and acquired through interaction (Eraut 2004), potentially impeding what has traditionally been referred to as "transfer". Although this dichotomy of learning (contexts) appears to be a reasonable categorization, in recent decades different authors (e.g., Beach 2003; Evans et al. 2010) have called attention to the more fundamental ways in which contexts of learning might differ, requiring an alternative conceptualization of transfer (Guile 2011; Tuomi-Gröhn et al. 2003).

What such an alternative conceptualization should also take into account is that the unidirectionality, typically from education to work, implied in transfer conceptualizations does not reflect the reality of most professional programs, wherein learners continuously move across contexts of learning (Beach 2003; Akkerman and Bakker 2012). For instance, a teacher enrolled in a part-time master program for professional development purposes may use cases from his or her work for educational assignments and immediately enact teaching strategies at work, thus continuously experiencing differences in what counts as learning, knowledge, and being a teacher.

\section{Boundary Crossing}

We understand learning across different contexts from a boundary-crossing perspective (Akkerman and Bakker 2011; Bronkhorst and Akkerman 2016). The term "boundary" refers to a sociocultural difference between contexts (Akkerman and Bakker 2011) that leads to ongoing learning being (temporarily) hampered, conceptualized as discontinuity in learning across contexts. When a learner fails to connect differences across contexts in his or her actions and/or understanding perspectives, this leads to a disturbed learning process (Akkerman and Bakker 2012). Such discontinuity can have serious consequences, such as disengagement and dropout ([Authors] 2016). Accordingly, there is increasing attention in both educational research and practice on how to create greater similarity between contexts of learning.

Yet, students' learning can be supported concurrently by different contexts of participation in and outside formal education (Guile 2011) when boundary crossing takes place (Akkerman and Bakker 2011; [Authors] 2016). Boundary crossing concerns the process of "negotiating and combining ingredients from different contexts to achieve hybrid situations" (Engeström et al. 1995, p.319), in other words (re-)establishing continuity across different contexts (Akkerman and Bakker 2011). Various large reviews on boundary crossing in and outside education (Akkerman and Bakker 2011; [Authors 2016]) show that boundaries indeed carry learning potential and that boundary crossing can promote learning by different learning mechanisms, stressing dialogic negotiation of meaning and practices. The benefits of learning across different contexts appear to be diverse, including increasing students' results (Alexander et al. 2008), improving students' understanding (Johansson and Sandberg 2012), developing new procedures or perspectives (Evans et al. 2010), and stimulating organizational change (Engeström 2001). 
By focusing on (dis)continuity in the learning process, a boundary-crossing perspective centrally orients the learner without rejecting the differences between contexts. In a situation where students continuously cross the boundaries between learning contexts, it is more helpful to focus on the relations between learning in formal education and at work, while considering contextual differences (Guile and Griffiths 2001; Guile 2011; Konkola et al. 2007).

\section{Boundary-Crossing Support}

Building on and extending the boundary-crossing and boundary object literature (e.g., Akkerman and Bakker 2011; Star 2010), Bronkhorst and Akkerman (2016) conceptually and empirically distinguished different ways to support boundary crossing, with corresponding exemplars in the context of part-time education, shown in Table 1 and detailed below.

Broker(ing) A first way to support boundary crossing is using members who participate in different contexts (Wenger 2010) to represent the work context in the program and vice versa (Bronkhorst and Akkerman 2016). A teacher can act as a broker (Akkerman and Bakker 2012) by sharing their own work experiences. Also, a person from a work context can be invited into the program, such as an expert who gives a guest lecture. Brokers may help to foster a good understanding of the different expectations of learners in different contexts (Furman and Barton 2006).

Boundary Objects Second, continuity across contexts can also be created by boundary objects (Star and Griesemer 1989), objects used in both contexts with a bridging function, that can adapt to the different contexts and simultaneously create a shared identity (Star 2010; Wenger 2010). Examples are concrete objects such as portfolios and product guidelines that the learner can use in both contexts (Akkerman and Bakker 2012). Additionally, a boundary object can be provided to link educational content to students' experiences (Bronkhorst and Akkerman 2016), by presenting problems that

Table 1 Ways to support boundary crossing and exemplars for part-time education

\begin{tabular}{ll}
\hline Ways to support boundary crossing & Exemplars for part-time education \\
\hline Broker(ing) & Teacher as representation \\
Boundary object & Expert as representation \\
& Concrete object with a bridging function \\
Hybrid practice & Content linked to students' interest \\
& Project-based learning \\
Boundary interactions & Problem-based learning \\
& Single-occasion visit to work setting \\
Degrees of freedom & Structural visit of work setting \\
& Reflection on interactions \\
& Validation of informal learning \\
& Practical possibilities \\
\hline
\end{tabular}


align with students' interests or experiences (Guile and Griffiths 2001), which may result in connections between contexts.

Hybrid Practices A third way is to create a hybrid practice, a learning environment which combines elements of education-based, formal learning and real-life, non-formal learning (Bouw et al. 2019). Hybrid forms of learning include problem-based and project-based learning, where learners solve a real-life problem or produce a concrete end product (Tynjälä et al. 2003). In project-based learning, a client organization is involved. Hybrid practices enable students to learn within and between different contexts (Guile and Griffiths 2001) and acquire the necessary skills for professional practice.

Boundary Interactions The fourth way to support boundary crossing is by organizing boundary interactions (Wenger 2010). Such interactions can be single occasions, such as a day trip to an organization, or a structural phase as part of the program (Bronkhorst and Akkerman 2016). In higher professional education, structural visits often occur in the form of internships. This period is recognized as a valuable trajectory for making transitions and relations between formal education and work (Akkerman and Bakker 2011). Here, the work context is educationalized to promote reflection, for example by including supervision, assignments, or reflective journaling (Ensor 2001).

Degrees of Freedom Bronkhorst and Akkerman (2016) stress the importance of degrees of freedom as an underlying condition to support boundary crossing. "Degrees of freedom" refers to the flexibility of programs in adapting to students' learning in other contexts, here specifically the freedom of programs to accommodate learning across contexts. One way to expand freedom is by validation of informal learning. Validation of learning from outside the program may result in a flexible study path and greater compatibility between work and education (Klarus et al. 2017). Second, practical possibilities for combining work and formal education are important in helping adult learners persist in participation (McGivney 2004) and planning of study activities in combination with work and personal activities (Adviescommissie 'Flexibel hoger onderwijs voor werkenden' 2014). Moreover, a flexible mode of delivery (De Boer et al. 2013) in time and space increases the opportunities for adults to participate (Broek et al. 2010) and combine learning activities.

\section{Present Study}

A large number of studies have examined ways to support boundary crossing, but most of these have focused on dual education programs. Less research has been conducted on boundary-crossing support in the context of part-time programs in higher education where the work setting is not part of the program. A better understanding of openended support for boundary crossing by students is vital for optimally organizing flexible continuous education. The research question is as follows: To what extent and in what ways do part-time programs support boundary crossing?

This question is explored through an explanatory sequential mixed-methods design, where the general understanding of the research problem provided by analysis of largescale quantitative data is explained in greater depth with qualitative data analysis (Creswell 2014). First, large-scale quantitative analyses are undertaken to determine 
whether there is a difference in perceived boundary-crossing support between part-time professional programs and whether factors postulated in the literature are related. Second, by capitalizing on the strengths of in-depth small-scale research, the ways to support boundary crossing - brokers, boundary object, hybrid practice, boundary interactions, degrees of freedom - are elucidated with purposefully selected case studies of programs differing in perceived boundary-crossing support. The purpose is to identify and define (potentially new) ways to support boundary crossing in the context of part-time programs in higher education.

\section{Method}

\section{The Dutch Educational System}

Professional education in the Netherlands is offered in two tracks: vocational education and training, and higher professional education. Both offer programs with a strong practical orientation for learning and professional training. This research is focused on higher professional education, given that vocational education and training programs are typically offered full-time, as most students are still (partly) of school age.

\section{Research Design}

An explanatory sequential mixed-methods design was implemented (see Fig. 1 and Table 2 for an overview of data sources). In the large-scale study, the difference in perceived boundary-crossing support (BCS) between programs and the ways in which programs can support boundary crossing (BCS-ways) are analyzed. In a small-scale study, the understanding of ways to support boundary crossing (BCS-ways) is expanded through qualitative analysis of multiple case studies.

By using multiple data sources, the conformability of the results is increased, and the impact of potential biases that can exist from a single source is reduced (Patton 1990). A three-step process was used to secure the quality of the findings of this mixedmethods design (Ivankova 2014). To begin, separate procedures were used to assess the quality of quantitative and qualitative data and findings. Next, to ensure the quality of the integrated conclusions, additional strategies specific to this type of mixed-methods design were implemented. The large-scale and small case studies were connected by selecting participants for the small-case study based on statistical results of the largecase study. By integrating quantitative and qualitative results, the mixed design will produce conclusions of higher quality (Ivankova et al. 2006).

\section{Large-Scale Study}

\section{Instrument}

To examine students' perception of higher education programs, an annual Dutch National Student Survey (NSS; Studiekeuze123, n.d.a) is conducted. The NSS is organized by Studiekeuze123, an independent foundation funded by the Ministry of 
Visual Model of the Research Design of this Study as recommended by Ivankova, Creswell \& Stick (2006)

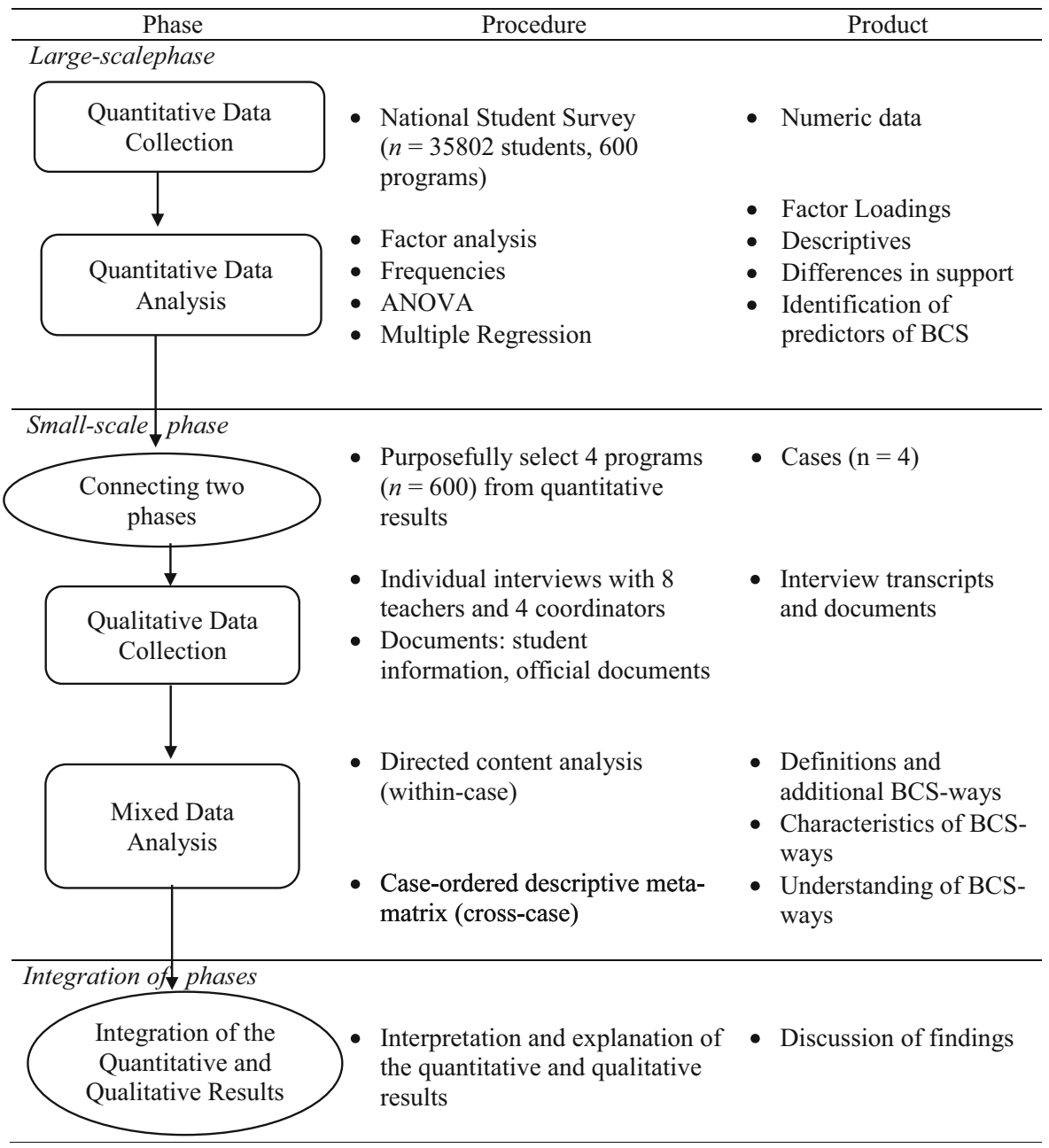

Fig. 1 Visual model of the research design of this study as recommended by Ivankova et al. (2006)

Education, Culture, and Science (Studiekeuze123, n.d.b). The data set in the NSS Benchmark file, conducted with the NSS in 2017 and 2018, was used for this research. The background information regarding the respondents, such as student identification, email address, type of program, and age, was delivered to Studiekeuze123 by the educational institutes. In accordance with General Data Protection Regulation (GDPR), personal data is not part of the Benchmark file.

The NSS explored students' evaluation of different aspects of their programs, including how they perceived their teachers' understanding of the professional practice, internship, and practical possibilities. These three aspects are strongly related to the ways to support boundary crossing (BCS-ways) - broker, boundary interaction, and degrees of freedom. Additionally, three items were selected that measured the extent of 


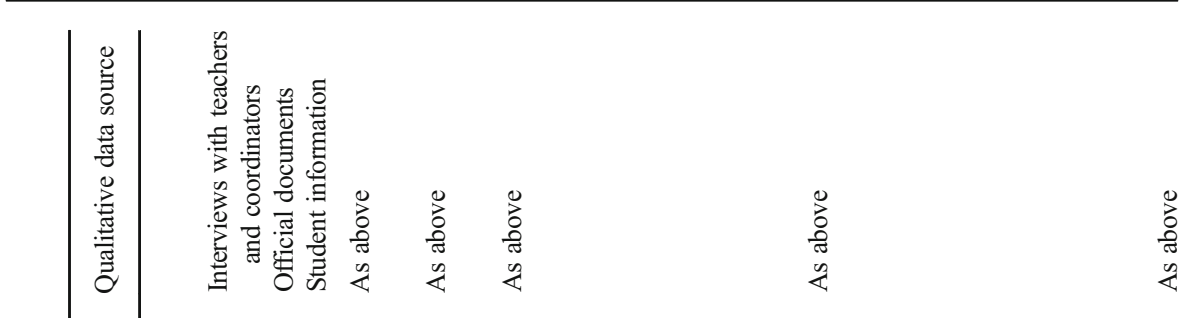

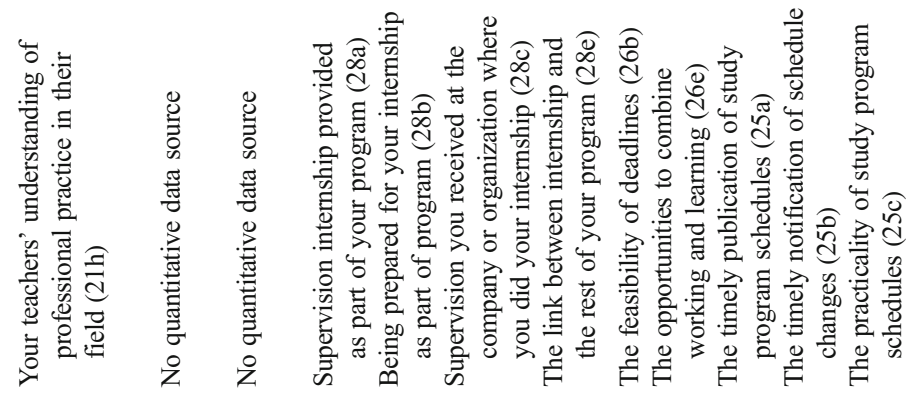

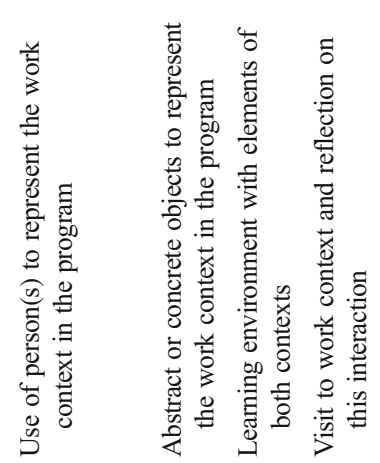

产

焉

论 


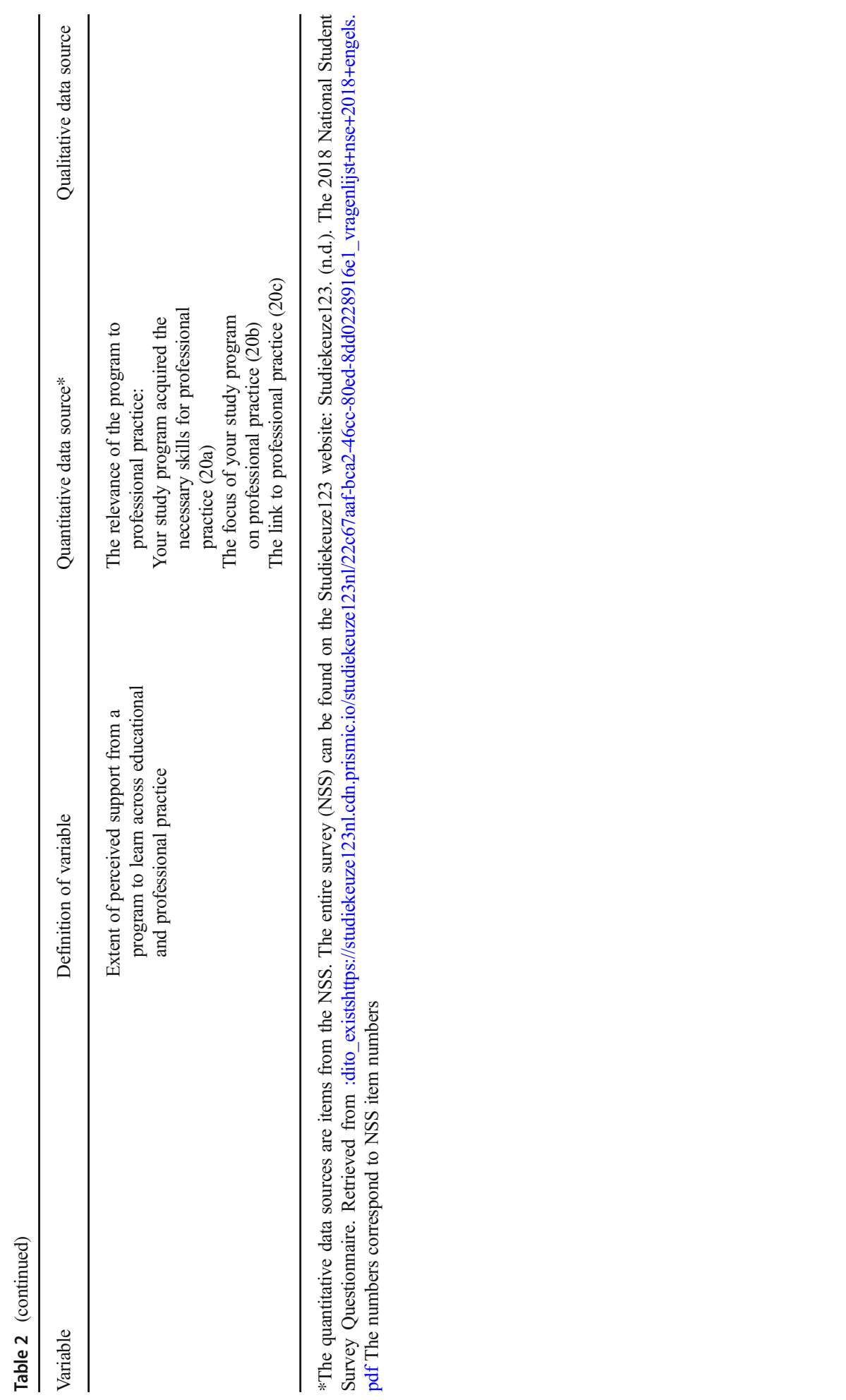


perceived boundary-crossing support (BCS). ${ }^{1}$ These data offered a unique opportunity to explore boundary-crossing support in the largest data set available on students in higher education in the Netherlands. Assessment indicated that the NSS data has high reliability and validity (Brenders 2013). Considering external validity, it is unknown whether the participants accurately represent the entire population based on the crosssection of the background variables for the entire population. Content validity was inferred based on the judgment of two fellow researchers (one with expertise in boundary crossing and the other in teaching in higher education), whose reservations resulted in the removal of the items for boundary object and two items for boundarycrossing support.

Participants A total of 547,624 students (59\% female, 41\% male, aged 12 to 100 years, $M=22.61, S D=5.91)$ completed the NSS. In this work, only the 600 part-time programs of 40 higher professional education institutes are of interest, resulting in a total of 35,802 respondents ( $61 \%$ female, $39 \%$ male, aged 16 to 100 years, $M=34.69$, $S D=9.99)$. There is a minor difference in age between bachelor and master students $(M=34.38, S D=9.74$ and $M=36.17, S D=10.51)$. The educational characteristics of programs and respondents are shown in Table 3.

All students in the Dutch higher education system were invited to participate by email, which contained a personal link to the survey. In cases of no response, three reminders were sent. This resulted in a voluntary response sample with an average response rate of $37 \%$ of the 744,000 students. This sample size is considered to provide high confidence and accuracy (Neuman 2014).

Data Collection To examine perceived BCS and the BCS-ways, items of the NSS were selected as a proxy measure (see Table 2). Statistical data for measuring convergent validity was not available, but the relation between variables and proxies was judged on theoretical grounds. Taking the theoretical framework into consideration, the items were reviewed on terms representing the definition of the variables and its exemplars (e.g. teacher as broker, internship, practicality) and terms representing the link to the work context (professional practice and work). All variables were measured by one to five statements, starting with the sentence "Please rate your satisfaction with...". Participants answered the items on a five-point Likert scale, ranging from "very dissatisfied" to "very satisfied", with a sixth "not applicable" option. The final score of the factors is the mean of the corresponding items.

Data Analysis Before starting the analysis, the construct validity of the NSS was tested with confirmatory factor analysis, after initial checks were conducted. "Broker" is excluded from the analysis, as it consists of one item. Bartlett's test of sphericity was significant, $\chi^{2}(66)=38,578.54, p<.001$. The Kaiser-Meyer-Olkin measure resulted in .86 , which falls into the range of being great (Hutcheson and Sofroniou 1999). A confirmatory factor analysis with four factors was adopted to extract factors. Oblique rotation is appropriate, since the factors are assumed to correlate. The cumulative variance of the factors was $70.47 \%$, which is more than acceptable (Field 2013). The factor pattern demonstrated a clear structure. All items that measure perceived

\footnotetext{
${ }^{1}$ Grouped items reflecting the variables are shown in Table 2.
} 
Table 3 Educational characteristics of programs $(N=600)$ and respondents $(N=35,802)$

\begin{tabular}{lllll}
\hline Characteristic & No. of programs & $\%$ & No. of respondents & $\%$ \\
\hline Level & & & & \\
Bachelor & 402 & 61 & 24,398 & 68 \\
Master & 137 & 31 & 9394 & 26 \\
Associate degree & 61 & 8 & 2010 & 6 \\
Sector & & & & 43 \\
Education & 220 & 37 & 15,362 & 1 \\
Agriculture & 12 & 2 & 465 & 9 \\
Technology & 81 & 14 & 3385 & 13 \\
Healthcare & 53 & 9 & 4697 & 13 \\
Economics & 108 & 18 & 4590 & 1 \\
Law & 9 & 2 & 431 & 1 \\
Social and community work & 106 & 18 & 6364 & \\
Language and culture & 11 & 2 & 508 & \\
\hline
\end{tabular}

boundary-crossing support had high loading on factor 1; all items that measured boundary interaction had high loading on factor 3. Factor 2 consisted of the items related to the time aspect of degrees of freedom, and factor 4 the items related to the study load aspect. All components had high reliability for research on a group level, with Guttman's $\lambda 2$ greater than .70 (Evers et al. 2010). Factor loadings, eigenvalues (the percent of variance attributable to each factor), the variance explained, and Guttman's $\lambda 2$ are shown in Table 4. The correlations between the scales capturing BCS and the BCS-ways varied from .42 to .58 .

First, descriptive statistics were used to explore variables. To measure the possible difference in (ways of providing) boundary-crossing support between programs, analysis of variance (ANOVA) was conducted for BCS and the BCS-ways broker, boundary interaction, and degrees of freedom. Additionally, multiple regression was used to examine whether BCS correlated with these BCS-ways. For theory testing, forced-entry multiple regression was the most appropriate method (Studenmund and Cassidy 1987). All missing values were deleted listwise.

\section{Large-Scale Results}

Table 5 presents descriptive statistics for the BCS and the BCS-ways broker, boundary interaction, and degrees of freedom. The mean scores show that on average, students experience (ways of) boundary crossing support, but the standard deviations indicate that the students' experiences diverge.

ANOVA was conducted to measure the difference in (ways of) boundary-crossing support between programs and showed that there was a significant linear trend of program on $\mathrm{BCS}, F(597)=6.68, p<.001$, ranging from $M=2.20$ for the lowest to $M=4.59$ for the highest program. A medium effect size of $\eta 2=.13$ was found (Cohen 1988), revealing that programs differed substantially in perceived boundary-crossing 
Table 4 Factor loading from rotated factor analysis: communalities, eigenvalues, percentages of variance, accumulative percentage of variance explained, and Guttman's $\lambda 2$

\begin{tabular}{|c|c|c|c|c|c|}
\hline \multirow[b]{2}{*}{ Factor name } & \multirow[t]{2}{*}{ Item no. } & \multicolumn{4}{|l|}{ Factor } \\
\hline & & 1 & 2 & 3 & 4 \\
\hline \multirow[t]{3}{*}{ Perceived boundary-crossing support } & $20 \mathrm{a}$ & .93 & & & \\
\hline & $20 \mathrm{~b}$ & .92 & & & \\
\hline & $20 \mathrm{c}$ & .67 & & & \\
\hline \multirow[t]{3}{*}{ Degrees of freedom - time } & $25 \mathrm{a}$ & & .93 & & \\
\hline & $25 \mathrm{~b}$ & & .93 & & \\
\hline & $25 \mathrm{c}$ & & .65 & & \\
\hline \multirow[t]{2}{*}{ Degrees of freedom - study load } & $26 \mathrm{~b}$ & & & & .89 \\
\hline & $26 \mathrm{e}$ & & & & .86 \\
\hline \multirow[t]{4}{*}{ Boundary interaction } & $28 \mathrm{a}$ & & & .85 & \\
\hline & $28 \mathrm{~b}$ & & &, 79 & \\
\hline & $28 \mathrm{c}$ & & & .73 & \\
\hline & $28 \mathrm{e}$ & & & .48 & \\
\hline Eigenvalue & & 4.91 & 1.60 & 1.01 & .87 \\
\hline$\%$ of variance explained & & 40.91 & 13.30 & 8.42 & 7.83 \\
\hline Accumulative variance explained & & & 54.22 & 62.64 & 70.47 \\
\hline Guttman's $\lambda 2$ & & .83 & .84 & .76 & .73 \\
\hline
\end{tabular}

The number of the item code corresponds to the number in the NSS questionnaire (Studiekeuze123, n.d.a)

support. Furthermore, ANOVA revealed that programs differed in students' evaluations of BCS-ways. Medium effect sizes were found for broker and boundary interaction $(<0.059)$, while the effect size for degrees of freedom was large $(<0.138)$ (Cohen 1988). Table 6 provides an overview of the statistics.

Multiple regression was used to test whether the BCS-ways correlated with BCS. Using the enter method, regression analysis found that broker $(\beta=.26, p<.001)$, boundary interaction $(\beta=.41, p<.001)$, and degrees of freedom $(\beta=.16, p<.001)$ were significant predictors of perceived boundary-crossing support (BCS) (Table 7),

Table 5 Frequency data for BCS and the ways to support boundary crossing broker (BR), boundary interaction $(\mathrm{BI})$, and degrees of freedom $(\mathrm{DoF})$

\begin{tabular}{lllll}
\hline & BCS & BR & BI & DoF \\
\hline No. & 28,440 & 31,055 & 8644 & 27,522 \\
Missing & 7362 & 4747 & 27,158 & 8280 \\
Mean & 3.65 & 3.92 & 3.57 & 3.52 \\
$S D$ & 0.82 & 0.88 & 0.77 & 0.76 \\
Minimum & 1 & 1 & 1 & 1 \\
Maximum & 5 & 5 & 5 & 5 \\
\hline
\end{tabular}

During factor analysis, missing values were deleted listwise 
Table 6 One-way analysis of variance for BCS and broker, boundary interaction, and degrees of freedom between part-time programs

\begin{tabular}{llrllll}
\hline Variable and source & $d f$ & \multicolumn{1}{l}{$S S$} & $M S$ & $F$ & $p$ & $\eta 2$ \\
\hline BCS & 597 & 2399.63 & 4.02 & 6.68 & $<.001$ & .13 \\
Broker & 598 & 2330.28 & 3.90 & 5.52 & $<.001$ & .10 \\
Boundary interaction & 275 & 472.84 & 1.72 & 3.12 & $<.001$ & .09 \\
Degrees of freedom & 579 & 2414.42 & 4.17 & 8.30 & $<.001$ & .15 \\
\hline
\end{tabular}

together explaining $44.10 \%$ of the variance in BCS, constituting grounds for in-depth exploration of BCS-ways.

\section{Small-Scale Study}

\section{Design}

The small-scale study is an in-depth follow-up examination of how programs support boundary crossing. In a comparative case study, where the focus is both within and across cases (Punch 2014), contrasting cases with high and low perceived boundarycrossing support helps to unravel what constitutes boundary-crossing support and whether additional factors play a role. To observe similar and contrasting results across cases (Yin 2003) and to increase the transferability of the results, the principle of maximum variation within a homogeneous group ${ }^{2}$ was adopted (Palinkas et al. 2015). To capture the variation in the sample, the level of perceived boundary-crossing support (low/high) and the program degree (bachelor/master) were included.

Sampling Procedure First, BCS scores for the part-time programs were standardized and programs were ranked in terms of perceived boundary-crossing support. Second, a sample of 10 part-time programs on each end of boundary-crossing support was identified, consisting of four groups of five programs: five bachelor and master programs with low and high BCS scores. All coordinators of the 20 programs received an invitation email. After 14 days of response time, four programs were purposefully selected from the responses, one program from each group, with a variety of sectors. In the low-support bachelor group, none of the program representatives were willing to participate. Consequently, a program with a slightly higher score was selected. Nonparticipation can be explained by failure to respond or refusal because of high workload.

Cases Four programs from the sample were selected to participate. The two bachelors are programs in the educational domain, where the high-support bachelor trains students for the (new) profession as a primary education teacher, and conversely, the

\footnotetext{
2 Therefore, associate degree programs were not included in the small-scale study.
} 
Table 7 Regression analysis summary for ways to support boundary crossing predicting perceived boundarycrossing support

\begin{tabular}{llllll}
\hline Variable & $B$ & $S E B$ & $\beta$ & $t$ & $p$ \\
\hline Broker & 0.26 & 0.01 & .29 & 28.50 & $<.001$ \\
Boundary interaction & 0.41 & 0.01 & .37 & 37.49 & $<.001$ \\
Degrees of freedom & 0.16 & 0.01 & .16 & 14.67 & $<.001$ \\
\hline
\end{tabular}

$R^{2}=.44(N=7428, p<.001$

low-support bachelor offers students a teacher certificate as a supplement to their former profession, allowing them to combine the two. The high-support master aims to train students to specialize in healthcare. Finally, the low-support master educates students for a new profession, at the same time offering the opportunity to achieve a professional registration. The characteristics of the four participating programs are shown in Table $8 .^{3}$

Data Collection To provide the richness and depth of case descriptions (Creswell 2014), multiple data sources were employed (Table 2). Official documents and data on teachers were collected with the help of the coordinators. Semi-structured interviews were conducted by the first author with four coordinators and eight teachers (all female ${ }^{4}$ and with 5 to 52 years of teaching experience), with each interview lasting from $30 \mathrm{~min}$ to an hour. After signed informed consent was obtained, participants were asked theorydriven interview questions, accompanied by a request to support answers with concrete examples (Table 9). Each interview was audio-recorded and transcribed. Pilot testing of the interview with two teachers unrelated to the research led to small changes in terminology and inclusion of more specific follow-up questions. Pilot testing of document analysis confirmed that relevant information could be identified.

Data Analysis To analyze the documents and interviews, directed content analysis (Hsieh and Shannon 2005) was adopted. An upfront coding scheme was developed based on the theoretical framework. In within-case analysis, BCS-ways were identified in the context of part-time professional higher education, and new ways of supporting boundary crossing were identified. For each exemplar (for an overview, see Table 1), an explicit example was selected and added to the coding scheme. With the cross-case analysis, qualitative and (if available) quantitative data from the four cases were displayed in a case-ordered descriptive meta-matrix (Miles et al. 2014). Cases were ordered from high to low according to BCS. First, meaningful units of data were selected and summarized in a short descriptive sentence. These sentences were then grouped and categorized according to meaning, similarities, and differences pertaining to BCS-ways, resulting in the inductive abstraction of the short descriptive sentences. By constant comparison, the interactivity between the data displayed gave rise to an understanding of the differences across and patterns between cases, resulting in the

\footnotetext{
${ }^{3}$ To maintain confidentiality, some details of the programs are omitted, as in a small country like the Netherlands, including these details could easily lead to programs being identified.

${ }^{4}$ Representative of the program staff.
} 
Table 8 Characteristics of participating programs

\begin{tabular}{|c|c|c|c|c|c|c|}
\hline Program & $\begin{array}{l}\text { BCS } \\
\text { score }\end{array}$ & Domain & Duration & $\begin{array}{l}\text { Role of work } \\
\text { setting }\end{array}$ & $\begin{array}{l}\text { Diversity } \\
\text { of } \\
\text { practice } \\
\text { field }\end{array}$ & $\begin{array}{l}\text { Key pedagogical } \\
\text { concepts }\end{array}$ \\
\hline $\begin{array}{l}\text { High-support } \\
\text { bachelor }\end{array}$ & 1.80 & $\begin{array}{l}\text { Primary } \\
\text { education }\end{array}$ & 4 years & $\begin{array}{l}\text { Internship, } \\
\text { at times } \\
\text { at own job }\end{array}$ & Small & $\begin{array}{r}\text { Meaningful } \\
\text { education }\end{array}$ \\
\hline $\begin{array}{l}\text { High-support } \\
\text { master }\end{array}$ & 1.93 & Healthcare & 2 years & $\begin{array}{l}\text { Internship, at times } \\
\text { at own job }\end{array}$ & Large & $\begin{array}{l}\text { Action-learning, } \\
\text { best-practice } \\
\text { trajectory }\end{array}$ \\
\hline $\begin{array}{c}\text { Low-support } \\
\text { bachelor }\end{array}$ & -.59 & Education & 2 years & $\begin{array}{l}\text { Validation of } \\
\text { learning } \\
\text { in students' job }\end{array}$ & Large & $\begin{array}{l}\text { Reflective } \\
\text { practitioner, } \\
\text { collaborative } \\
\text { learning }\end{array}$ \\
\hline $\begin{array}{l}\text { Low-support } \\
\text { master }\end{array}$ & -1.12 & $\begin{array}{l}\text { Language \& } \\
\text { culture }\end{array}$ & 4 years & $\begin{array}{l}\text { Validation of } \\
\text { learning } \\
\text { in students' job }\end{array}$ & Small & $\begin{array}{l}\text { Project learning, } \\
\text { concurrent } \\
\text { education }\end{array}$ \\
\hline
\end{tabular}

development of the descriptions of the exemplars and a summary of the manifestations of BCS-ways (see Table 10 for code definitions and examples from the data).

In terms of quality assurance, mixed-data triangulation allowed the researcher to compare and contrast (Patton 1999), and a rich, thick description of the research procedure (Ivankova et al. 2006; Assarroudi et al. 2018) enabled transferability. An audit trail was created based on reflexive notes taken during the process (Akkerman et al. 2008), and an external auditor formatively evaluated (De Kleijn and Van Leeuwen 2018) the complete data collection and analysis process, leading to some small adjustments in the matrix and result section.

All quotations in this article were translated from Dutch into English. Small adjustments were made to improve readability.

\section{Within-Case Results}

All programs recognized the learning potential of boundary crossing for students. A teacher explained:

What I love to see is that they can put learned skills into practice right away. [...] You can immediately use learning from school to become more valuable to the company where you work. You can see that those who are aware of that make enormous leaps in their development. (Willemijn, low-support master)

Many representatives of the programs mentioned the added value of the diversity of the learner contexts. They also noted that they believed that previous education and work experience leads to more motivated, focused students compared with full-time students. 
Table 9 Interview questions for coordinators and teachers of part-time programs

Questions

Follow-up questions

Background information

What is your name?

In which program do you teach?

Which courses?

How many years of experience do you have?

Do you have other work besides your job as a teacher?

Can you, in short, describe this job?

Other support for boundary crossing by students

How do you experience training of part-time student in comparison with full-time students?

What do part-time students need from you as a teacher/coordinator?

What are the advantages and disadvantages of working with part-time students?

How do you support part-time students in combining education and work?

Boundary object, hybrid practice

Do you link educational content to the interest of the work experience of students in your class?

Do you refer to concrete examples of cases that students can experience in their working life? How do you do this? Can you give an example?

Do you use tools in your teaching that are developed Can you think of a competence profile for graduates or with external partners?

a format or guidelines for products?

Can you describe an example of such a tool?

Are there projects where students work on real-life problems?

Can you describe an example of such a project? Are companies involved in the development of those projects?

Do these projects deliver concrete end products?

\section{Broker, boundary interactions}

Do the teachers in the program have another job, Can you give examples of these other jobs?* besides their job as a teacher?**

Do you work with experts from the working fields of For example, experts who give guest lectures or students? workshops? Can you give an example?

How much freedom do you feel you have to design Can you give an example? the program in the way you prefer?

Who decides on the curriculum?

Do you have the freedom to adjust or add parts of the course?

Do you integrate elements of the work context in your education curriculum?

Do you visit projects or organizations outside the program?

Can you describe the modes of learning that you offer? Think of face-to-face, distance or online learning, blended, discussions, seminars, etc.*

Do you think it is possible for students to combine work and education?

What makes you feel this way?

[if no] What do you lack?

[if yes] Can you give an example?

[if no] Why not?

[if yes] Can you give an example?

Are the distance/online learning moments instead of or in addition to the face-to-face learning moments?*

What do students say about this?

How can you help students to improve this?

\section{Finishing question}

Are there important issues in the context of part-time students that have not been discussed?

*The questions with an asterisk are only for the coordinators. 
Table 10 Ways to support boundary crossing and underlying conditions with exemplars, definition, and examples from the data

\begin{tabular}{llll}
\hline $\begin{array}{l}\text { Key } \\
\text { concept }\end{array}$ & Exemplars & Definition & Example from data \\
\hline
\end{tabular}

\begin{tabular}{|c|c|c|c|}
\hline \multicolumn{4}{|c|}{ Ways to support boundary crossing } \\
\hline \multirow[t]{3}{*}{ Broker } & $\begin{array}{l}\text { Teacher as } \\
\text { representa- } \\
\text { tion }\end{array}$ & $\begin{array}{l}\text { Teacher who works both in the } \\
\text { program and in a work-practice re- } \\
\text { lated to the program }\end{array}$ & $\begin{array}{l}\text { "Many teachers are, besides their } \\
\text { work at [program], active as a } \\
\text { professional artist, teacher, } \\
\text { educator, coach, researcher, or } \\
\text { consultant. [...] Their combined } \\
\text { professional practices, in which } \\
\text { they switch between different roles } \\
\text { and contexts, reflect the current } \\
\text { professional practice of our } \\
\text { students." (OD-LSB) }\end{array}$ \\
\hline & $\begin{array}{l}\text { Expert as } \\
\text { representa- } \\
\text { tion }\end{array}$ & $\begin{array}{l}\text { Person from a work context who is } \\
\text { invited into the program. Examples } \\
\text { are an expert who gives guest } \\
\text { lectures or a committee with } \\
\text { professionals discussing the } \\
\text { content and relevance of the } \\
\text { program. }\end{array}$ & $\begin{array}{l}\text { "By means of a series of lectures by } \\
\text { different specialists and offices, a } \\
\text { variety of projects will be shown } \\
\text { and discussed. Apart from the } \\
\text { content of (recent) projects, lec- } \\
\text { turers are also asked to give } \\
\text { 'behind-the-scenes' previews of } \\
\text { how their approach can be } \\
\text { successful, but also what kind of } \\
\text { challenges they face." (SI-LM) }\end{array}$ \\
\hline & $\begin{array}{l}\text { Class as } \\
\text { representa- } \\
\text { tion }\end{array}$ & $\begin{array}{l}\text { Heterogeneous student population } \\
\text { participating in program and work } \\
\text { context, leading to identification of } \\
\text { or reflection on own methods and } \\
\text { processes }\end{array}$ & $\begin{array}{l}\text { "The mix of professions, functions, } \\
\text { experiences, and ages offers unique } \\
\text { opportunities for collaboration and } \\
\text { learning opportunities for both } \\
\text { students and teachers." (OD-HM) }\end{array}$ \\
\hline \multirow[t]{2}{*}{$\begin{array}{l}\text { Boundary } \\
\text { object }\end{array}$} & $\begin{array}{r}\text { Concrete } \\
\text { object }\end{array}$ & $\begin{array}{l}\text { Object with a bridging function, } \\
\text { which is simultaneously used in the } \\
\text { program and work practice. } \\
\text { Examples are portfolios or } \\
\text { internship blogs }\end{array}$ & $\begin{array}{l}\text { "The practice portfolio is more than a } \\
\text { record of projects [...] It provides } \\
\text { insight into the skills and } \\
\text { knowledge gained in practice }[\ldots] \\
\text { The portfolio is a reflection on their } \\
\text { own actions and includes a } \\
\text { development plan." (SI-HM) }\end{array}$ \\
\hline & Linked content & $\begin{array}{l}\text { Teacher links educational content to } \\
\text { students' interests or relates it to } \\
\text { students' work, e.g., an authentic } \\
\text { learning task. }\end{array}$ & $\begin{array}{l}\text { "That learning process during } \\
\text { [program] has its own dynamic: the } \\
\text { action-learning cycle. This is the } \\
\text { central didactic concept of the } \\
\text { program, where students take } \\
\text { questions and/or materials from } \\
\text { their own practice as a starting } \\
\text { point." (SI-HM) }\end{array}$ \\
\hline $\begin{array}{l}\text { Hybrid } \\
\text { practice }\end{array}$ & Problem-based & $\begin{array}{l}\text { Students study a problematic situation } \\
\text { adapted from the real world and } \\
\text { find solutions. }\end{array}$ & $\begin{array}{l}\text { "Through research by design and the } \\
\text { development of new products (for } \\
\text { housing and care), in the studio } \\
\text { students aim to investigate how the } \\
\text { elderly part of the population can } \\
\text { be and stay (re)integrated within } \\
\text { society." (SI-LM) }\end{array}$ \\
\hline & Project-based & & $\begin{array}{l}\text { "Together with the program and the } \\
\text { organization he is working for, the }\end{array}$ \\
\hline
\end{tabular}


Table 10 (continued)

\begin{tabular}{|c|c|c|c|}
\hline $\begin{array}{l}\text { Key } \\
\text { concept }\end{array}$ & Exemplars & Definition & Example from data \\
\hline
\end{tabular}

$\begin{array}{ccc}\begin{array}{c}\text { Boundary } \\ \text { interac- }\end{array} & \text { Single } & \text { Single-occasion visits to a work } \\ \text { tions } & \text { occasion } & \begin{array}{l}\text { context, such as a trip to an } \\ \text { organization or conference }\end{array}\end{array}$

Structural interaction

Reflection on interaction

\section{Degrees of Validate freedom informal learning}

Practical
possibilities

Mode of delivery
Students work on a real-life problem, producing a concrete end product for a client organization. organization or conference

Structural visit to a work context, where the student functions in an organization, often an internship

Supervision on internship provided as part of your program or what you received at the organization

\section{Underlying conditions}

Flexibility to recognize and validate informal learning. For example, an opportunity to validate informal learning outcomes or adjust an assignment to a work project

Possibility and practicality for students to combine working and studying, e.g., by learning opportunities at flexible hours and timely publication of schedule

Learning opportunities via various modes of delivery to offer flexibility, e.g., distance learning and online delivery of standard courses as an alternative to campus-based learning

Involvement of the staff in each other's activities and responsibilities. They know the common topics of other courses and communicate this consistent with the students student completes the assignment so that the problem is ultimately solved in the form of a best practice." (SI-HM)

"The lessons are scarce; you only have two lesson evenings in a week. [...] So you have to make a lot of choices. Therefore, we occasionally take a trip.” (T-HB)

"Internships play an important role in [the program]. The student's functioning as an art teacher or educator is best reflected in acting in authentic practice." (SI-LB)

"During the internship, the supervisor makes a classroom observation and discusses the learning progress with the internship supervisor and the student." (SI-LB)

"This concurrent education offers students experience and education beyond the curriculum [...] Students are required to find a job in a firm and work a minimum of 20 hours a week. Progress will be evaluated through a series of portfolio assessments." (OD-LM)

"We work relatively little with group assignments. That is a deliberate choice because students are here occasionally, and are also very busy with another job and a family." (C-HB)

"We provide our entire program online. We started with that because we also have international students. [...] So they do not come to [location]. That is allowed because our program is set up in such a way that everything is offered digitally." (T-HM)

"The fact that the students enjoy studying with us has a lot to do with team involvement. This team is strongly involved with the students and each other. We know what common themes are in other courses [...] We are on the same page." (T-HM) 
Table 10 (continued)

\begin{tabular}{|c|c|c|c|}
\hline $\begin{array}{l}\text { Key } \\
\text { concept }\end{array}$ & Exemplars & Definition & Example from data \\
\hline & $\begin{array}{l}\text { Clear } \\
\text { communica- } \\
\text { tion }\end{array}$ & $\begin{array}{l}\text { Clear communication about } \\
\text { expectations, procedures, } \\
\text { assessment, and amount of } \\
\text { flexibility. The availability of the } \\
\text { staff for questions, despite limited } \\
\text { contact hours }\end{array}$ & $\begin{array}{l}\text { "We discuss exactly what you have to } \\
\text { do, how you can tackle this. [...] } \\
\text { Because part-time students have } \\
\text { little time and therefore have more } \\
\text { focus on what needs to be done." } \\
\text { (T-HB) }\end{array}$ \\
\hline Supervision & & $\begin{array}{l}\text { The staff provides supervision, } \\
\text { support, or training during the } \\
\text { program, e.g., in coping with the } \\
\text { combination work-study or profes- } \\
\text { sional positioning. }\end{array}$ & $\begin{array}{l}\text { "The feasibility for part-time students } \\
\text { improves, especially because they } \\
\text { all work and their position is } \\
\text { changing during the program, with } \\
\text { reflective practice training. They } \\
\text { get a new impulse; they start to } \\
\text { think differently about things." } \\
\text { (T-HM) }\end{array}$ \\
\hline
\end{tabular}

Abbreviations of sources: $\mathrm{T}=$ interview teacher, $\mathrm{C}=$ interview coordinator, $\mathrm{SI}=$ student information, $\mathrm{OD}=$ official document, $\mathrm{HB}=$ high-support bachelor, $\mathrm{HM}=$ high-support master, $\mathrm{LB}=$ low-support bachelor, $\mathrm{LM}=$ low-support master

On the other hand, the programs recognized the difficulties for learners. All respondents stated that combining work and study is challenging, focusing on the practical challenges involved with job and family commitments.

\section{Identification of BCS-Ways}

All of the upfront BCS-ways emerging from the analysis are presented in Table 10. The analysis revealed additional ways, detailed below.

Class as Representation The majority of respondents stated that the heterogeneous student population offered learning potential by representing work contexts in the program. Besides the teacher and the expert, the class could function as a broker in part-time higher education.

To illustrate this, the study guide of the high-support master included a description: "The mix of professions, functions, experiences, and ages offers unique opportunities for collaboration and learning for both students and teachers." In addition, a teacher of this master explained:

It is a very diverse audience, which is why the learning teams function that well. In all their innocence from their own perspective, the students say 'we operate like this', and then others say 'we act very differently'. They learn a lot from each other. That's what they say. And they really appreciate it. (Paulien, high-support master)

Degrees of Clarity Various possibilities were mentioned for shaping a setting where students could fruitfully learn across contexts. Considering these possibilities, there 
appeared to be a second underlying condition for boundary crossing: degrees of clarity. The need for clarity alongside the flexibility that degrees of freedom provide is reflected in this quote:

I think you have to indicate the coherence in the curriculum, that they understand that we, you know, that they have clarity: when do we have lessons, at what time, from whom, what should we have been doing now, because they are just very busy. Clarity. And flexibility. That balance. (Helga, coordinator high-support master)

Several coordinators and teachers indicated that clarity is often requested, especially for part-time students with more external constraints arising from work and family commitments. To illustrate this with a quote: "Part-time students know that they have little time and are therefore focused on what needs to be done. In contrast, full-time students think "if I start a week in advance, then I will make a lot of progress." (Emma, teacher high-support bachelor)

First, this clarity can refer to the coherence of the program. A team of teachers who are involved in the activities and responsibilities of colleagues can communicate in a coherent way and monitor important aspects of the program. Teachers expressed the wish for a clear connection between courses, for example:

The fact that the students enjoy studying with us has a lot to do with team involvement. This team is strongly involved with the students and each other. We know what common themes are in other courses [...] We are on the same page. (Paulien, teacher high-support master)

Also, this clarity concerns clear communication about expectations, procedures, assessment, and the amount of flexibility. Several coordinators and teachers noted the importance of this, illustrated by phrases such as "discuss exactly what they have to do" (Emma, teacher high-support bachelor), "clear communication" (Janna, coordinator low-support bachelor), and "expectation management" (Melanie, teacher high-support master, and Janna, coordinator low-support bachelor). To sum up, "degrees of clarity" can be described as the coherence and transparency of programs with regard to the expectations, obligations, and possibilities for students.

Supervision Additionally, a third underlying condition for fostering boundary-crossing support is the staff supervision of their students. Teachers and coordinators described the importance of supervision of professional positioning or reflective practice training on how to cope with the combination of work and study and their position at work, including personal circumstances. A teacher described:

That is also one of my responsibilities, if they [students] are bothered by something or run into something during the year. For example, students say: 'I really want to achieve this competency', or 'I have those ambitions, but I no longer see my growth, and I talked to my boss about it but it doesn't work', lots of conversations about that. How do you approach that? How can you make that clear? (Willemijn, low-support master) 


\section{Cross-Case Results}

Large-scale results showed that the four programs in the small-scale study offered boundary-crossing support, although the amount of support differed. Perceived boundary-crossing support between the high- and low-support cases differed significantly, $t(202)=5.78, p<.001$. Patterns and contrasts between high- and low-support programs were analyzed using a case-ordered descriptive meta-matrix and are detailed below. Further analysis revealed some remarkable issues in the high-support programs, which together provide insight into the differences in perceived BCS (Table 11):

This is why students are so satisfied with their preparation for professional practice. The knowledge they learn here is provided within the context of their future profession, and they can immediately apply it in their current jobs. This has an accelerating effect. (Emma, teacher high-support bachelor)

Broker Some significant contrasts $(t(203)=9.55, p<.001)$ in broker(ing) were found, with $M=4.50$ for the high-support versus $M=3.75$ for the low-support programs, and expert as representation showing the most apparent difference. All programs reported frequent use of an expert, for example for a guest lecture or as members of practice field committees. Interestingly, coordinators and teachers of the high-scoring programs mentioned that they preferred teachers as a representation over an external expert, to maintain coherence in the curriculum. This indicated that ensuring a team of teachers with diverse expertise in line with the various backgrounds of students, and only adding guest experts with additional expertise, could be an effective way to support boundary crossing.

Furthermore, all program reported that the majority of their staff acted as teachers as representation. A coordinator who also has another job described the added value for students: "As an expert, you develop self-assurance that helps you thrive. [...] I can offer them that confidence. Also, I think I can make other connections than they do as a result of my experience." (Irene, low-support master) Additionally, three of the four

Table 11 Summary of the manifestations of ways to support boundary crossing in high-support programs

\begin{tabular}{ll}
\hline Way to support boundary crossing & Manifestation in high-support programs \\
\hline Broker & $\begin{array}{c}\text { Team with diverse expertise, exclusively invite external expert } \\
\text { with a new perspective } \\
\text { Situations from practice are the starting point of the learning process } \\
\text { Boundary object }\end{array}$ \\
$\begin{array}{l}\text { The real-life problem as a key pedagogical approach } \\
\text { Bybrid practice }\end{array}$ & $\begin{array}{c}\text { Provide good preparation for and supervision of internship } \\
\text { Opportunities for distance learning, no mandatory attendance, }\end{array}$ \\
and flexible deadlines \\
Degrees of clarity & Strong connections between team members with frequent exchange \\
of information & Adequate pre-course information and tutor sessions
\end{tabular}


programs acknowledged the class as a representation of the out-of-school contexts. A heterogeneous student population increases learning opportunities. Teachers and coordinators described processes in the class as exchanging knowledge and procedures, redefining their own position and qualities, or taking up another's perspective.

Boundary Object Various concrete boundary objects were identified in the four programs. Two striking examples are the internship blog and the contents practice portfolio, where students provided insight into their learning processes in the program and internship organization or employer. However, marked differences were observed in the way programs linked the educational content to students' experiences. The two highsupport programs explicitly stated that they used situations from practice as the starting point of the learning process. On the contrary, the low-support programs reported struggles to align with students' interests or experiences, referring to, for example, the diverse student population.

Hybrid Practice Concerning problem-based learning, high- and low-support programs differed. In the former, programs reported the use of real-life problems as a key pedagogical approach. The master adopted an action-learning cycle, and the bachelor related all theory explicitly to cases from students' practice. Low-support programs also worked with cases, but their use and application were less consistent and explicit.

All programs adopted a varying amount of project-based learning with client organizations. Whereas one might expect both masters to work with a high level of project-oriented learning based on their pedagogical vision, the limited use of projects in the low-support master was remarkable. The coordinator of this master motivated this:

"It is complicated working on real assignments because you are in competition with agencies that earn their money, so as an institute we cannot compete with the practice field. That's not fair. We deprive the source of income of the persons we have trained." (Irene)

Boundary Interaction Boundary interactions had a substantial role in the programs, consisting mostly of structural interactions. In both bachelors, students conduct an internship throughout the entire program and are supervised by both the program and their internship organization concurrently (reflection on interaction). There was a significant difference $(t(113)=5.65, p<.001)$ in the evaluation of boundary interaction, with $M=4.29$ for the high-support bachelor and $M=3.36$ for the low-support bachelor. Data suggest that the low scores of the latter can be explained by the supervision of the program and preparation for the internship as part of the program. Conversely, master students have a job in the practice field and validate their informal learning; these interactions are categorized in degrees of freedom.

In addition, the majority of the participants stated that single-occasion interactions are scheduled incidentally, due to limited time and inflexible calendars of working students. The extracurricular activities organized for the whole student population are often not easily accessible for part-timers with a tight schedule. 
Degrees of Freedom Significant differences $(t(187)=8.08, p<.001)$ were found in degrees of freedom between high- and low-support programs, with a mean of 4.11 and 3.44 , respectively. The findings were confirmed by the qualitative data, showing noteworthy differences in practical possibilities and mode of delivery. The highsupport master had the highest evaluation on this aspect and reported the most flexibility by means of opportunities for distance learning, no mandatory attendance, and flexible deadlines. Teacher Melanie explained: "The entire program is available online [...] What they like depends on the learning style of students. Some students say that they join every week [...] but others come when they feel the need."

Comparing high and low programs, no apparent differences were found for validation of informal learning. The bachelor programs had special tracks for some students but did not provide set opportunities for validation of informal learning. On the contrary, both master programs defined a substantial part of the program where work experience could be validated, namely the best-practice trajectory and concurrent education. Surprisingly, the low-support master had the most substantial role for work experience in the program.

Degrees of Clarity Data suggest that programs differed strongly in the extent to which they offered clarity. First, in relation to coherence, participants of the high-support master explained that strong connections between team members and exchange of information facilitated student support: "If I want to discuss something, I can immediately go to colleagues from my team. Action is taken immediately [...] Of course, that is what students appreciate." (Melanie, teacher)

Secondly, three of the four programs emphasized the importance of clear communication, and full and accurate information on course content and procedures, which is particularly important for adult learners with a tight schedule. High-support programs reported on multiple implementations of clear communication, such as adequate precourse information and tutor sessions. The low-support bachelor struggled for coherent communication but indicated some improvements; the low-support masters did not indicate this issue.

Supervision No significant differences were found in the supervision of students. The importance of guidance and support was mentioned by participants of all programs.

\section{Discussion}

Continuous education is facilitated by part-time professional programs in higher education. A key challenge for part-time programs is providing support for students in connecting what they learn in the program to their work, which in contrast to dual education, is not part of and is typically very different from the program. To better understand such open-ended boundary-crossing support in higher professional education, this explanatory sequential mixed-methods study was conducted. The large-scale results comparing 600 part-time programs confirm that students report varying degrees of perceived boundary-crossing support, with a medium effect size of $\eta 2=.13$. In-depth comparisons of four purposefully selected programs indicated that factors postulated in 
the literature on boundary crossing (i.e., brokers, boundary objects, hybrid practices, boundary interactions, degrees of freedom) and new factors (i.e., degrees of clarity and supervision) are ways to support boundary crossing.

While most of the findings are consistent with prior research on boundary crossing and part-time education, there are also important differences. First, participants in the current study described students as brokers of outside (professional) contexts, yielding negotiation of meaning and perspective-taking. These findings resonate with those of Tanggaard (2007), who described a similar process involving peers challenging and inspiring each other with different perspectives and experiences. However, the heterogeneous class as a representation enabling brokering was not explicated by Bronkhorst and Akkerman. The literature Bronkhorst and Akkerman reviewed stressed how, when a student is the only one who crosses between contexts, brokering can easily be too great a challenge, especially for "non-mainstream" students. This difference can be explained by the relatively higher age and experience among part-time students in higher education, as well as the fact that all students in the program have similar boundaries to cross, in contrast to situations in which only minority students face that challenge. All things considered, one must not forget that brokering can be educative but also challenging, and requires program support (see also Akkerman and Bakker 2011).

Second, this study further specified degrees of freedom as experienced by the student, complementing descriptions in the literature from a teacher and program perspective (Bronkhorst and Akkerman 2016). The study was also able to break down degrees of freedom into practical possibilities, mode of delivery, and validation of informal learning. These components are similar to those reported in the study by Broek et al. (2010) on adult learning in higher education, but go beyond the more theoretical use of the term in the literature. Furthermore, the study highlighted the importance of degrees of clarity parallel to degrees of freedom, phrased by coordinator Helga as "the balance between flexibility and clarity" (p.26). Flexibility is experienced as such only if all options and procedures are clear; otherwise, flexibility can easily become lack of guidance. This also agrees with the findings of McGivney (2004), who reported on factors that might increase persistence in adult education, such as adequate information. Together, degrees of freedom and clarity highlight how boundary-crossing support not only resides in the direct interaction of programs with students, but also requires organizational support.

The identification of these new ways to support boundary crossing may be related to the heterogeneous student population that characterizes part-time programs, with each student having a greater number of unique work and family commitments, and thus requiring more freedom, clarity, and supervision from programs (for similar reasoning, see Guile 2011). However, there is no a priori reason to assume that these methods for supporting boundary crossing are not valuable in other situations, as each student in any given educational setting participates in different contexts (e.g., school, home, hobbies, leisure, online) on a daily basis (Akkerman and Bakker 2011; Bronkhorst and Akkerman 2016), and time scarcity requires careful management of these activities. More generally, the means of boundary-crossing support fit with more general recommendations for contemporary education, for instance in terms of authenticity, personalization, flexibility, and transparency (Biesta et al. 2011; Brown, 2012; OECD 2013).

More specifically for professional programs, the way that the work contexts of students are positioned in part-time programs comes to the fore. Contrasting high- and low-support 
programs indicates that positioning the work context of the student as the starting point of the learning process can provide support for boundary crossing. High-support programs seem to actively help students combine ingredients from the program and work context, and as a result share the boundary-crossing efforts and responsibility with students. Contrarily, low-support programs appreciate the diversity of work contexts but appear to struggle to integrate this within the program, leaving integration up to the student. Taking a shared boundary-crossing approach, such as working with cases from the students' work context and stimulating them to test assignments at work, will centrally orient the learner without negating differences in contexts and is generally considered a more effective adult learning practice (Viskovic 2006).

To our knowledge, this study is the first to employ an explanatory sequential mixedmethods design to study boundary-crossing support. We see the design as a strength of the study, as it allows us to capture both trends and details. Building on the guidelines provided by Ivankova et al. (2006), our design focused on a strong integration of mixed methods throughout the conduct of the study. Such integration is often called for in mixed-methods research methodology, but is rarely achieved (Onwuegbuzie et al. 2018). With the programs as the units of analysis in both phases of our study, a nested sample, and conceptual integration in the analytic phase, a more complete understanding of boundary-crossing support was attained (Yin 2006).

\section{Limitations and Future Research}

An important limitation of this study is the use of NSS items as proxy measures, which poses a threat to construct validity. NSS items were not formulated in the context of boundary crossing, and the variables boundary object and hybrid practice could not be measured in the large-scale study. Regardless, the corresponding terms in the theoretical framework and items, the closely related subject (combining work and study), and the similar context (part-time students in higher education) indicate an acceptable degree of measuring the defined constructs. The consistency of the findings in the small-scale study using alternative sources is also encouraging (Carlson and Herdman 2012). To summarize, there are indications for validity legitimation (Onwuegbuzie and Johnson 2006), but a note of caution is due here.

Furthermore, a remark should be made regarding boundary-crossing support. It was a deliberate choice to use the students' perceptions in the large-scale study via the NSS and to gather additional data on boundary-crossing support in part-time programs via documents and interviews with coordinators and teachers. However, the latter could be characterized as intended boundary-crossing support, since it is not demonstrated that students perceive such support. Moreover, all participants in the small-scale case study described part-time students as more motivated and focused than full-time students. Boundary crossing has been shown to enhance student motivation (Davidson and Major 2014), but it is also plausible that motivated students make a greater effort to integrate learning across contexts. Therefore, boundary crossing cannot be explained solely by the support of the program. Further research could explore students' capacity, role, and responsibilities in boundary crossing.

This research can be seen as the first step in understanding boundary-crossing support in the context of part-time higher professional education. Additional research is needed to test and extend the findings to other countries with other educational 
systems. In future work, alternative explanations for differences in boundary-crossing support could also be examined, including the program degree (bachelor - master) and sector, as the reluctance among low-support masters to include structural boundary interactions in order to avoid appropriating work from their graduates already indicates that sector plays a role. Additionally, boundary-crossing support might need to be adaptive to students within programs, as indicated by the quote from Elvira in the introduction. We acknowledge that new entrants, career switchers, and career enhancers might have different reasons for studying, and in addition, another relation to the field of practice of their (future) employment. As this falls outside the scope of the case study, a valuable next step would be to research the differences in boundary-crossing support and opportunities for boundary crossing between students.

\section{Implications for Practice}

Notwithstanding these limitations, the findings of our study suggest that pulling in students' different professional contexts in part-time higher education programs is important for learning in and across contexts. The findings also provide actionable strategies for coordinators and teachers of part-time higher education programs to support boundary crossing. In the introduction, a perspective was expressed by Elvira as to how programs can integrate learning from work and education in a group of students with diverse expertise and needs. As has become evident from this study, a diverse team of teachers and external experts and implementation of cases from the work context of students can bring the diversity of work settings into the classroom. Next, validation of out-of-school learning and testing assignments at work improves the role of work experience in education and the compatibility between the two. These suggestions offer opportunities for programs to engage with students with highly divergent professional participation in a meaningful way.

More generally, adopting a boundary-crossing perspective might raise awareness of potential benefits, but also the challenges of learning across contexts, especially for students in part-time higher education programs. Therefore, it would seem that the responsibility for making connections across contexts of learning must be one that is actively shared between the program and the student.

Open Access This article is distributed under the terms of the Creative Commons Attribution 4.0 International License (http://creativecommons.org/licenses/by/4.0/), which permits unrestricted use, distribution, and reproduction in any medium, provided you give appropriate credit to the original author(s) and the source, provide a link to the Creative Commons license, and indicate if changes were made.

\section{References}

Adviescommissie 'Flexibel hoger onderwijs voor werkenden'. (2014). Adviesrapport Flexibel hoger onderwijs voor volwassenen [Advisory report Flexible higher education for adults]. Retrieved from: :dito_existshttps:/www.rijksoverheid.nl/documenten/rapporten/2014/03/12/flexibel-hoger-onderwijsvoor-volwassenen.

Akkerman, S., Admiraal, W., Brekelmans, M., \& Oost, H. (2008). Auditing quality of research in social sciences. Quality \& Quantity, 42(2), 257-274.

Akkerman, S. F., \& Bakker, A. (2012). Crossing boundaries between school and work during apprenticeships. Vocations and Learning, 5(2), 153-173. 
Akkerman, S. F., \& Bakker, A. (2011). Boundary crossing and boundary objects. Review of Educational Research, 81(2), 132-169.

Alexander, K., Bozick, R., \& Entwisle, D. (2008). Warming up, cooling out, or holding steady? Persistence and change in educational expectations after high school. Sociology of Education, 81(4), 371-396.

Assarroudi, A., Heshmati Nabavi, F., Armat, M. R., Ebadi, A., \& Vaismoradi, M. (2018). Directed qualitative content analysis: The description and elaboration of its underpinning methods and data analysis process. Journal of Research in Nursing, 23(1), 42-55.

Beach, K. (2003). Consequential transitions: A developmental view of knowledge propagation through social organizations. In T. Tuomi-Gröhn \& Y. Engeström (Eds.), New perspectives on transfer and boundary crossing (pp. 39-62). Amsterdam: Elsevier.

Biesta, G. (2006). What's the point of lifelong learning if lifelong learning has no point? On the democratic deficit of policies for lifelong learning. European Educational Research Journal, 5(3-4), 169-180.

Biesta, G., Field, J., Hodkinson, P., Macleod, F. J., \& Goodson, I. F. (2011). Improving learning through the lifecourse: Learning lives. Routledge.

Bouw, E., Zitter, I., \& de Bruijn, E. (2019). Characteristics of learning environments at the boundary between school and work - a literature review. Educational Research Review, 26(1), 1-15.

Brenders, P. (2013). Response, reliability, and validity of the Dutch national student survey, presented at EAIR 35th Annual Forum, Rotterdam, 2013. Retrieved from :dito_existshttps://www.researchgate. net/publication/257815511_Response_reliability_and_validity_of the_Dutch_National_Student_Survey.

Broek, S., \& Hake, B. J. (2012). Increasing participation of adults in higher education: Factors for successful policies. International Journal of Lifelong Education, 31(4), 397-417.

Broek, S., de Jonge, J. \& Hake, B. (2010) Hoger onderwijs en Levenlang leren. Internationaal vergelijkende studie. Een onderzoek in opdracht van Ministerie van Onderwijs, Cultuur en Wetenschap [Higher education and lifelong learning. International comparative study. A study commissioned by the Ministry of Education, Culture and Science.]. Zoetermeer: Research voor Beleid/Panteia.

Bronkhorst, L. H., Akkerman, S. F. (2016). At the boundary of school: Continuity and discontinuity in learning across contexts. Educational Research Review, 19, 18-35.

Carlson, K. D., \& Herdman, A. O. (2012). Understanding the impact of convergent validity on research results. Organizational Research Methods, 15(1), 17-32.

Cohen, J. (1988). Statistical power analysis for the behaviors science (2nd ed.). New Jersey: Laurence Erlbaum Associates, Publishers, Hillsdale.

Creswell, J. W. (2014). A concise introduction to mixed methods research. California: Sage Publications.

Davidson, N., \& Major, C. H. (2014). Boundary crossings: Cooperative learning, collaborative learning, and problem-based learning. Journal on excellence in college teaching, 25.

De Boer, H., Epping, E., Faber, M., Kaiser, F., \& Weyer, E. (2013). Continuing Higher Education. Center for Higher Education Policy Studies (CHEPS). Retrieved from: :dito_existshttp://www.ihem. info/themereports/ContinuingHigherEducationFiveCountryStudyCHEPS.pdf

De Kleijn, R., \& Van Leeuwen, A. (2018). Reflections and Review on the Audit Procedure: Guidelines for More Transparency. International Journal of Qualitative Methods, 17(1).

Endedijk, M. D., \& Bronkhorst, L. H. (2014). Students' learning activities within and between the contexts of education and work. Vocations and learning, 7(3), 289-311.

Engeström, Y. (2001). Expansive learning at work: Toward an activity theoretical reconceptualization. Journal of Education and Work, 14, 133-156.

Engeström, Y., Engeström, R., \& Kärkkäinen, M. (1995). Polycontextuality and boundary crossing in expert cognition: Learning and problem solving in complex work activities. Learning and instruction.

Ensor, P. (2001). From preservice mathematics teacher education to beginning teaching: A study in recontextualizing. Journal for Research in Mathematics Education, 296-320.

Eraut, M. (2004). Informal learning in the workplace. Studies in Continuing Education, 26(2), $247-273$.

European Commission (1995). Teaching and Learning: towards the learning society (Brussels, European Commission). Retrieved from :dito_existshttp://europa.eu/documents/comm/white_ papers/pdf/com95_590_en.pdf.

Evans, K., Guile, D., Harris, J., \& Allan, H. (2010). Putting knowledge to work: A new approach. Nurse Education Today, 30(3), 245-251.

Evers, A., Sijtsma, K., Lucassen, W., \& Meijer, R. R. (2010). The Dutch review process for evaluating the quality of psychological tests: History, procedure, and results. International Journal of Testing, 10(4), 295-317.

Field, A. P. (2013). Exploratory factor analysis. Discovering statistics using SPSS (4th ed.). (pp.665-719) London: Sage Publication.

Field, J. (2000). Lifelong learning and the new educational order. United Kingdom: Trentham Books. 
Fuller, A. (2001). Credentialism, adults and part-time higher education in the United Kingdom: An account of rising take up and some implications for policy. Journal of Education Policy, 16(3), 233-248.

Furman, M., \& Barton, A. C. (2006). Capturing urban student voices in the creation of a science minidocumentary. Journal of Research in Science Teaching, 43(7), 667-694.

Guile, D. (2011). Apprenticeship as a model of vocational 'formation' and 'reformation': The use of foundation degrees in the aircraft engineering industry. Journal of Vocational Education \& Training, 63(3), 451-464.

Guile, D., \& Griffiths, T. (2001). Learning through work experience. Journal of Education, 14(1).

Hsieh, H. F., \& Shannon, S. E. (2005). Three approaches to qualitative content analysis. Qualitative Health Research, 15(9), 1277-1288.

Hutcheson, G. D., \& Sofroniou, N. (1999). The multivariate social scientist: Introductory statistics using generalized linear models. London: Sage Publications Ltd.

Ivankova, N. V. (2014). Implementing quality criteria in designing and conducting a sequential QUAN $\rightarrow$ QUAL mixed methods study of student engagement with learning applied research methods online. Journal of Mixed Methods Research, 8(1), 25-51.

Ivankova, N. V., Creswell, J. W., \& Stick, S. L. (2006). Using mixed-methods sequential explanatory design: From theory to practice. Field Methods, 18(1), 3-20.

Johansson, I., \& Sandberg, A. (2012). Learning and knowledge development in preschool teacher education and practicum. Early Child Development and Care, 182(7), 907-920.

Klarus, R., Peeters, A., \& Joosten-ten Brinke, D. (2017). Toetsen en valideren van leeruitkomsten in flexibel onderwijs [Testing and validating learning outcomes in flexible education]. Toetsen in het hoger onderwijs (pp. 95-107). Bohn Stafleu van Loghum, Houten.

Konkola, R., Tuomi-Gröhn, T., Lambert, P., \& Ludvigsen, S. (2007). Promoting learning and transfer between school and workplace. Journal of Education and Work, 20(3), 211-228.

McGivney, V. (2004). Understanding persistence in adult learning. Open Learning: The Journal of Open Distance and e-Learning, 19(1), 33-46.

Miles, M. B., Huberman, A. M., \& Saldana, J. (2014). Qualitative data analysis, a method sourcebook (3rd ed.). London, United Kingdom: SAGE Publications.

MvOCW (Ministerie van Onderwijs, Cultuur en Wetenschap). (2018). Deelrapport - De staat van het hoger onderwijs 2018 [Subreport - The state of higher education 2018]. Retrieved from :dito_existshttps://www. onderwijsinspectie.nl/documenten/rapporten/2018/04/11/deelrapport-de-staat-van-het-hoger-onderwijs

Neuman, W. L. (2014). Understanding research. Essex, England: Pearson/Allyn and Bacon.

OECD (Organisation for Economic Co-operation and Development). (2013). Education Today 2013: The OECD Perspective. Retrieved from: :dito_existshttps://www-oecd-ilibrary-org.proxy.library.uu. nl/education/education-today-2013_edu_today-2013-en.

Onwuegbuzie, A. J., Hitchcock, J., Natesan, P., \& Newman, I. (2018). Using fully integrated Bayesian thinking to address the $1+1=1$ integration challenge. International Journal of Multiple Research Approaches, 10(1), 666-678.

Onwuegbuzie, A. J., \& Johnson, R. B. (2006). The validity issue in mixed research. Research in the Schools, $13(1), 48-63$.

Palinkas, L. A., Horwitz, S. M., Green, C. A., Wisdom, J. P., Duan, N., \& Hoagwood, K. (2015). Purposeful sampling for qualitative data collection and analysis in mixed method implementation research. Administration and Policy in Mental Health and Mental Health Services Research, 42(5), 533-544.

Patton, M. Q. (1999). Enhancing the quality and credibility of qualitative analysis. Health Services Research, 34(5 Pt 2), 1189.

Patton, M. Q. (1990). Qualitative evaluation and research methods. Washington: SAGE Publications, inc..

Punch, K. F. (2014). Collecting Qualitative Data. Introduction to social research: Quantitative and qualitative approaches. ( $3^{\text {rd }}$ ed.) London: Sage.

Schaap, H., Baartman, L., \& De Bruijn, E. (2012). Students' learning processes during school-based learning and workplace learning in vocational education: A review. Vocations and Learning, 5(2), 99-117.

Star, S. L. (2010). This is not a boundary object: Reflections on the origin of a concept. Science, Technology, \& Human Values, 35(5), 601-617.

Star, S. L., \& Griesemer, J. R. (1989). Institutional ecology translations' and boundary objects: Amateurs and professionals in Berkeley's Museum of Vertebrate Zoology, 1907-39. Social studies of science, 19(3), 387-420. Distributed artificial intelligence (pp. 37-54). San Mateo, CA: Morgan Kaufmann.

Studenmund, A. H., \& Cassidy, H. J. (1987). Using econometrics: A practical guide. Boston: Little Brown..

Studiekeuze123. (n.d.a). The 2018 National Student Survey Questionnaire. Retrieved from :dito existshttps://studiekeuze123nl.cdn.prismic.io/studiekeuze123n1\%2F22c67aaf-bca2-46cc-80ed8dd0228916e1_vragenlijst+nse+2018+engels.pdf. 
Studiekeuze123. (n.d.b). Studiekeuzeinformatie Nationale Studenten Enquête - Studiekeuzeinformatie. Retrieved from :dito_existshttp://www.studiekeuzeinformatie.nl/nse.

Tanggaard, L. (2007). Learning at trade vocational school and learning at work: Boundary crossing in apprentices' everyday life. Journal of Education and Work, 20(5), 453-466.

Tuomi-Gröhn, T., Engeström, Y., \& Young, M. (2003). From transfer to boundary-crossing between school and work as a tool for developing vocational education: An introduction. In T. Tuomi-Gröhn \& Y. Engeström (Eds.), Between school and work: New perspectives on transfer and boundary-crossing (pp. 1-18). Amsterdam, Netherlands: Pergamon.

Tynjälä, P., Välimaa, J., \& Sarja, A. (2003). Pedagogical perspectives on the relationships between higher education and working life. Higher Education, 46(2), 147-166.

Vereniging Hogescholen (VH) (2018). Hbo deeltijdonderwijs in de lift, flexibiliteit loont [HBO part-time education on the rise, flexibility is rewarded]. Retrieved from :dito_existshttps://www. vereniginghogescholen.nl/standpunten/leven-lang-leren

Viskovic, A. (2006). Becoming a tertiary teacher: Learning in communities of practice. Higher Education Research \& Development, 25(4), 323-339.

Wenger, E. (2010). Communities of practice and social learning systems: the career of a concept. In Social learning systems and communities of practice (pp. 179-198). Springer, London.

Yin, R. (2006). Mixed methods research: Are the methods genuinely integrated or merely parallel? Research in the Schools, 13(1), 48-63.

Yin, R. (2003). Case study research: Design and methods (3rd ed.). Thousand Oaks: Sage.

Publisher's Note Springer Nature remains neutral with regard to jurisdictional claims in published maps and institutional affiliations.

Margit Arts is a part-time master's student in Educational Sciences at Utrecht University. She works as an educational designer at the Centre for Lifelong Learning and Educational Innovation of the University of the Arts Utrecht.

Larike Bronkhorst is assistant professor at the Department of Education of Utrecht University. Her research focuses on learning, development, and collaboration across contexts (including but not limited to school, home, work, leisure, online) from a boundary-crossing perspective. Larike also teaches in the research and academic master program Educational Sciences and in different teacher education master programs. 